\title{
A Comparison of Methods to Assess the Excitability of Lower Motoneurones
}

\author{
Ivan G. Milanov
}

\begin{abstract}
The purpose of this investigation was to compare three methods of assessing the excitability of lower motoneurones - TA-reflex, H-reflex and F-wave - in 120 patients with spastic hemiparesis following a stroke. The $\mathrm{H}$-reflex was recorded from the soleus muscle after submaximal electrostimulation of the tibial nerve. The T-Achilles (TA) reflex was recorded from the soleus muscle after percussion of the Achilles tendon. The F-wave was recorded in the distal limb muscles after supramaximal electrostimulation of the median, ulnar, fibular and tibial nerves. The patient's healthy side was used as a control. The TA-reflex, H-reflex and F-wave showed increased amplitudes on the spastic side. All amplitude ratios: TA/M, H/M, Fmax/M and Fmean/M were increased. The H-reflex thresholds were decreased. The F-wave duration, persistence and number of phases were also increased on the spastic side. Despite clinically decreased muscle tone, there were no changes in TA or H-reflex parameters after treatment. On the other hand, F-wave parameters tended to normalize after treatment in all groups. In conclusion, the F-wave is a more sensitive method than the TA and $\mathrm{H}$-reflexes in assessing the excitability of the lower motoneurone.
\end{abstract}

RÉSUMÉ: Comparaison des méthodes d'évaluation de l'excitabilité des neurones moteurs périphériques. Le but de cette étude est de comparer trois méthodes d'évaluation de l'excitabilité des motoneurones périphériques - réflexe tendineux achilléen (TA), réflexe $\mathrm{H}$ et onde $\mathrm{F}$ - chez 120 patients avec hémiparésie spastique suite à un accident cérébro-vasculaire. Le réflexe $\mathrm{H}$ a été enregistré à partir du muscle soléaire après électrostimulation submaximale du nerf sciatique poplité interne. Le réflexe TA a été enregistré à partir du muscle soléaire après percussion du tendon d'Achilles. L'onte $\mathrm{F}$ a été enregistrée dans les muscles distaux des membres après électrostimulation supramaximale des nerfs médian, cubital, sciatique poplité externe et sciatique poplité interne. Le côté sain du patient a été utilisé comme contrôle. L'amplitude du réflexe $\mathrm{TA}$, du réflexe $\mathrm{H}$ et de l'onde $\mathrm{F}$ étaient augmentées du côté spastique. Tous les rapports d'amplitude, TA/M, H/M, Fmax/M et Fmoyenne/M étaient augmentés. Le seuil des réflexes $H$ était diminué. La durée de l'onde $\mathrm{F}$, la persistance et le nombre de phases étaient aussi augmentés du côté spastique. Malgré un tonus musculaire diminué, il n'y avait pas de changement dans les paramètres de réflexes TA ou $\mathrm{H}$ après traitement. D'autre part, les paramètres de l'onde $\mathrm{F}$ avaient tendance à se normaliser après traitement dans tous les groupes. En conclusion, l'onde F est une méthode d'évaluation plus sensible de l'excitabilité du motoneurone périphérique que les réflexes TA et $H$.

Can. J. Neurol. Sci. 1992; 19:64-68

The T- and H-reflexes described by Hoffmann in 1918, are widely used in assessing lower motoneurone excitability. As they are monosynaptic reflexes, their amplitudes depend on the excitability of the motoneurone. ${ }^{1}$ A more precise index of motoneurone excitability is the ratio of their amplitudes to the amplitude of the M-response: the T/M and H/M ratios. ${ }^{1,2}$ The $\mathrm{H}-$ reflex thresholds with minimal and maximal amplitude also depend on the excitability of the lower motoneurone. ${ }^{3,4}$

In 1950, Magladery and McDougal described the F-wave ${ }^{5}$ as a recurrent discharge of antidromically activated motoneurones. ${ }^{6-8}$ F-wave parameters also depend on the excitability of the lower motoneurone. ${ }^{9}$

The sensitivity of these methods can be assessed after some change in motoneurone excitability. Motoneurone excitability is decreased in "spinal shock". In such cases, the $\mathrm{T}$ and $\mathrm{H}$ reflex amplitudes, as well as the $\mathrm{T} / \mathrm{M}$ and $\mathrm{H} / \mathrm{M}$ ratios are decreased ${ }^{1}$ and the persistence and mean $\mathrm{F}$-wave amplitude are also decreased. ${ }^{10.11}$ In spasticity, when motoneurone excitability is increased, there is an increase in the T-reflex amplitude, T/M ratio, ${ }^{1,12-14} \mathrm{H}$-reflex amplitude and $\mathrm{H} / \mathrm{M}$ ratio $^{2,14,15}$ and the persistence $^{8,16,17}$ and mean amplitude of the F-wave. ${ }^{17-19}$ The $\mathrm{H}$ reflex thresholds were decreased in spasticity. ${ }^{3,4}$ After treatment of spasticity when the motoneurone excitability is reduced, the physiological findings are controversial. Decreases of the $\mathrm{T}$ and $H$ reflex amplitudes and $T / M$ and $H / M$ amplitude ratios have been reported after treatment of spasticity with benzodiazepines, ${ }^{20,21}$ Baclofen, ${ }^{14,15}$ tizanidine, ${ }^{22,23}$ chronic cerebellar ${ }^{13,24,25}$ and spinal ${ }^{26,27}$ electrostimulation. However, other papers have reported no change in these parameters after treatment with the same myorelaxants..$^{2.12,21.28-31}$ There are no F-wave

From the Institute of Neurology, Psychiatry and Neurosurgery, Bulgarian Medical Academy, Sofia

Received January 9, 1991. Accepted in final form August 13, 1991

Reprint requests to: Ivan Milanov, Institute of Neurology, Psychiatry \& Neurosurgery, Bul. "Lenin" - IV km. Sofia 1113, Bulgaria 
data after treatment with myorelaxants, although a decrease in the F-wave persistence and mean amplitude was found after chronic cerebellar electrostimulation. ${ }^{13}$

The excitability of the lower motoneurone is important. The purpose of this study was to compare these three methods for assessing the excitability of the lower motoneurone excitability in a large group of patients with spastic hemiparesis.

\section{Patients}

One hundred and twenty patients ( 87 women and 33 men) with spastic hemiparesis after stroke were evaluated. The mean age was $57 \pm 8.6$ years (from 34 to 76 years). The mean duration of the disease was 36 months. Only patients with no clinical or electromyographical evidence of peripheral nerve injury took part in this investigation. The patients were divided into four groups of 30 . Patients in each group received a different treatment of spasticity for a mean of $24.9 \pm 7.2$ days. There were no significant differences ( $p>0.1$ ) between the groups for age, duration of the disease, duration of treatment, sex, degree of spasticity or weakness. Since results of the electromyographic methods are bilaterally identical in healthy persons and since no changes on the healthy side in spastic hemiplegia have ever been reported, ${ }^{16,32.33}$ the patients' unaffected side was used as a control. All patients signed an informed consent.

Patients in three of the groups were treated with myorelaxants as follows: Baclofen (Polfa-Polland) - mean daily dose 54 $\pm 12 \mathrm{mg}$. Myolastan (Sanofi-France) - mean daily dose $102 \pm$ $36 \mathrm{mg}$. Sirdalud (Sandoz-Switzerland) - mean daily dose $16 \pm$ $6 \mathrm{mg}$. The individual daily doses varied according to the patients' tolerance, and was divided into three oral doses.

The fourth group was treated with electroacupuncture. The acupuncture points for treatment of spasticity were as follows: ${ }^{34,35}$ Hegu (LI-4), Quchi (LI-11), Leique (Lu-7), Zusanli (St-36), Neiting (St-44), Weizhong (UB-40), Chengshan (UB57), Kunlun (UB-60), Taichong (Liv-3), Yanglingquan (GB-34), Huantiao (GB-30), Tongli (H-5), Yashu (Gov-2), Jizhong (Gov6 ), Yamen (Gov-15). The points were needled and electrostimulation with a biphasic current of $100 \mathrm{~Hz}$ was applied for half an hour at an intensity comfortable to the patient. A mean of 16 daily treatment sessions were given. The electroacupuncture used in this investigation resembles spinal and muscle electrostimulation.

\section{MethodS}

\section{Clinical Methods}

Neurological examination was performed before and after treatment. The well known five point scales for muscle tone (Ashworth scale), muscle force (Medical Research Council Scale) and tendon reflexes were used in the neurological examination. ${ }^{36,37}$ Babinski's sign and ankle clonus were registered when present.

\section{Electromyographical Methods}

"Medicor" (Hungary) electromyographic equipment with a memory scope was used. Since all electromyographic measurements were obtained both before and after treatment, special care was taken to standardize the examination. Identical recording locations were used and the maximal amplitude of the Mresponse was the same in both sessions. ${ }^{38}$ Since the parameters being measured are stable in normal individuals over time, ${ }^{32.33 .38}$ any change in these parameters after treatment should be caused by the treatment. During the examination the patients were as relaxed as possible and only recordings without visible background EMG activity were used for analysis. The following methods were used:

(i) The H-reflex was recorded by a monopolar surface electrode over the soleus muscle ${ }^{4}$ with a reference electrode on the opposite Achilles tendon. A $1 \mathrm{~ms}$ duration square wave electrical pulse was applied to the tibial nerve in the popliteal fossa. ${ }^{4}$ The stimuli were given every 10 seconds. The stimulus strength and site of stimulation was adjusted so as to obtain an H-reflex with the lowest threshold and then with the maximal amplitude. ${ }^{4}$ The maximal (peak to peak) reflex amplitude was evaluated by cursors. The stimulus thresholds to elicit an $\mathrm{H}$-reflex with minimal amplitude and an $\mathrm{H}$-reflex with maximal amplitude were measured.

(ii) T-Achilles (TA) reflex was recorded from the same electrodes as used for the H-reflex studies. ${ }^{38}$ The reflex was produced by percussion on the Achilles tendon with a neurological hammer. ${ }^{39}$ The maximal (peak to peak) reflex amplitude was evaluated by cursors.

(iii) F-waves were recorded by bipolar surface electrode from abductor pollicis brevis, abductor digiti quinti, extensor digitorum brevis and abductor hallucis muscles. The median, ulnar, fibular and tibial nerves were respectively stimulated (cathode proximal) at wrist or ankle with supramaximal $0.5 \mathrm{~ms}$ duration square-wave voltage pulses. ${ }^{18}$ Twenty stimulations for each nerve were performed. The F-wave maximal amplitude (peak-to-peak), duration and number of phases were evaluated by cursors. The F-wave persistence was evaluated as a percentage of the F-waves obtained to the number of stimulations. The mean amplitude and the ratios of F-wave maximal amplitude to M-response amplitude (Fmax/M) and of F-wave mean amplitude to $\mathrm{M}$-response amplitude (Fmean/M) were calculated.

\section{Statistical Methods}

Paired student's t-tests and ANOVA with Neuman-Keuls method were used to compare the parameters of electromyographic methods. The Wilcoxon t-test was used to compare the parameters of neurological examination. Regression and correlation analyses were also used. ${ }^{40}$

\section{RESULTS}

\section{Before Treatment}

Significant increases $(\mathrm{p}<0.001)$ of TA-reflex amplitude and TA/M amplitude ratio was found on the spastic side (Table 1). On the spastic side there was also an increase $(p<0.001)$ of $H$ reflex amplitude and $\mathrm{H} / \mathrm{M}$ ratio (Table 2 ). The thresholds for the H-reflex with minimal and with maximal amplitude were decreased $(p<0.001)$.

On the spastic side maximal and mean F-wave amplitudes, as well as Fmax/M and Fmean/M amplitude ratios were significantly $(\mathrm{p}<0.001)$ increased (Table 3 ). The F-wave duration was prolonged $(\mathrm{p}<0.001)$ and the persistence and number of phases were significantly $(\mathrm{p}<0.001)$ increased.

Moderate $(r>0.3)$ to considerable $(r>0.5)$ correlations were found between the amplitude parameters of all three electromyographic methods (Table 4). There were no correlations 
$(r<0.3)$ between the other electromyographic parameters or between disease duration and electromyographic parameters. The correlations between electromyographic measurements and the clinical measurements of muscle tone, force and reflexes were poor $(r<0.3)$.

\section{After Treatment}

The results from the neurological examination revealed decreased muscle tone $(p<0.01)$ on the spastic side with a mean of 50 percent (Table 5). There were no differences between the different modes of treatment except that the effect of Baclofen on reducing muscle tone was less than the other treatments $(p<0.01)$. Muscle force, tendon hyperreflexia, Babinski and ankle clonus were not generally influenced by the treatments $(\mathbf{p}<0.1)$. However, a reduction in the patients with Babinski sign $(\mathrm{p}<0.01)$ was observed after Baclofen treatment.

The results from the electromyographic examination revealed no influence $(0.1>p>0.05)$ from any treatment on TA-reflex parameters (Table 1$)$. There was also no effect $(0.1>p$ $>0.05$ ) by any treatment on H-reflex parameters (Table 2).

All parameters of the F-wave in all four groups tended to normalize (Table 3 ). The mean and maximal F-wave amplitudes, amplitude ratios, persistence and number of phases

\section{Table 1: Mean Values of T-Achilles Reflex Parameters}

\begin{tabular}{lcccrrrr}
\hline \hline Parameters & Healthy Side & \multicolumn{2}{c}{ Spastic Side } & \multicolumn{2}{c}{$\begin{array}{c}\text { Spastic Side } \\
\text { After Treatment }\end{array}$} \\
\cline { 2 - 8 } & \multicolumn{1}{|c}{ SD } & $\overline{\mathbf{X}}$ & SD & $\overline{\mathbf{X}}$ & SD \\
\hline Maximal & & & & & & \\
amplitude $\mathrm{mV}$ & 2.14 & 2.01 & 4.28 & 3.41 & 3.88 & 3.07 \\
TA/M Ratio - \% & 17.48 & 11.3 & 38.64 & 21.41 & 35.55 & 20.44 \\
\hline
\end{tabular}

The mean values are calculated across all four patient groups, as there are no significant $(\mathrm{p}<0.1)$ differences between them.

$\bar{X}$ - mean value

$\mathrm{SD}$ - standard deviation

Table 2: Mean Values of H-Reflex Parameters

\begin{tabular}{|c|c|c|c|c|c|c|}
\hline \multirow[t]{2}{*}{ Parameters } & \multicolumn{2}{|c|}{ Healthy Side } & \multicolumn{2}{|c|}{ Spastic Side } & \multicolumn{2}{|c|}{$\begin{array}{c}\text { Spastic Side } \\
\text { After Treatment }\end{array}$} \\
\hline & $\overline{\overline{\mathbf{X}}}$ & SD & $\overline{\mathbf{X}}$ & SD & $\overline{\mathbf{X}}$ & $\overline{\text { SD }}$ \\
\hline $\begin{array}{l}\text { Maximal } \\
\text { amplitude } \mathrm{mV}\end{array}$ & 3.4 & 2.4 & 6.3 & 3.6 & 5.9 & 3.8 \\
\hline $\mathrm{H} / \mathrm{M}$ ratio $-\%$ & 29.2 & 13.7 & 52.1 & 20.9 & 49.9 & 19.6 \\
\hline $\begin{array}{l}\text { Threshold of } \\
\text { H-reflex with } \\
\text { minimal amplitude } \\
-\mathrm{V}\end{array}$ & 181.5 & 71.3 & 138.3 & 69.0 & 142.6 & 48.9 \\
\hline $\begin{array}{l}\text { Threshold of } \\
\text { H-reflex with } \\
\text { maximal amplitude }\end{array}$ & & & & & & \\
\hline$-\mathrm{V}$ & 220.9 & 72.4 & 176.7 & 74.3 & 192.9 & 69.8 \\
\hline
\end{tabular}

The mean values are calculated across all four patient groups, as there are no significant $(\mathrm{p}<0.1)$ differences between groups.

$\overline{\mathrm{X}}$ - mean value

$\mathrm{SD}$ - standard deviation decreased and the duration was shortened with treatment $(p<$ $0.001)$. There were no differences $(p>0.1)$ between the four treatments.

There were no changes in any of the electromyographic measurements on the healthy side after treatment $(p>0.1)$.

\section{Discussion}

The results of this study reveal that all three electromyographic methods for assessing the excitability of the lower motoneurone are significantly altered by spasticity. The maximal amplitudes of the TA- and H-reflex and their amplitude

Table 3: Mean Values of F-Wave Parameters

\begin{tabular}{|c|c|c|c|c|c|c|}
\hline \multirow[t]{2}{*}{ Parameters } & \multicolumn{2}{|c|}{ Healthy Side } & \multicolumn{2}{|c|}{ Spastic Side } & \multicolumn{2}{|c|}{$\begin{array}{c}\text { Spastic Side } \\
\text { After Treatmen }\end{array}$} \\
\hline & $\overline{\mathbf{X}}$ & SD & $\overline{\mathbf{X}}$ & SD & $\overline{\mathbf{X}}$ & SD \\
\hline $\begin{array}{l}\text { Maximal amplitude } \\
\mathrm{mV}\end{array}$ & 0.4 & 0.2 & 1.0 & 0.4 & 0.6 & 0.2 \\
\hline Mean amplitude $-m V$ & 0.2 & 0.1 & 0.6 & 0.3 & 0.3 & 0.15 \\
\hline Fmax $/ \mathrm{M}$ ratio $-\%$ & 5.3 & 3.3 & 12.4 & 5.3 & 7.1 & 3.3 \\
\hline Fmean/M ratio $-\%$ & 2.2 & 1.5 & 7.8 & 3.5 & 3.6 & 2.0 \\
\hline Duration - ms & 5.6 & 1.3 & 12.5 & 3.1 & 7.6 & 1.9 \\
\hline Persistence - \% & 55.7 & 15.3 & 92.0 & 13.1 & 62.0 & 12.1 \\
\hline Number of Phases & 2.1 & 0.3 & 4.0 & 1.0 & 2.4 & 0.6 \\
\hline
\end{tabular}

The mean values are calculated across all four patient groups and four peripheral nerves $(n=480)$, as there are no significant $(p<0.1)$ differences between them.

$\overline{\mathrm{X}}$ - mean value

$\mathrm{SD}$ - standard deviation

Table 4: Values of the Correlation Coefficient (r) Between Parameters of TA, H-Reflexes and F-Wave

\begin{tabular}{|c|c|c|c|c|}
\hline Parameters & $\begin{array}{l}\text { TA-reflex } \\
\text { amplitude }\end{array}$ & $\mathbf{T A} / \mathbf{M}$ & $\begin{array}{c}\text { H-reflex } \\
\text { amplitude }\end{array}$ & $\mathbf{H} / \mathbf{M}$ \\
\hline H-reflex amplitude & 0.7 & 0.4 & - & - \\
\hline $\mathrm{H} / \mathrm{M}$ ratio & 0.5 & 0.6 & - & - \\
\hline $\begin{array}{l}\text { F-wave maximal } \\
\text { amplitude }\end{array}$ & 0.2 & - & 0.3 & 0.1 \\
\hline F-wave mean amplitude & de 0.1 & - & 0.3 & 0.2 \\
\hline
\end{tabular}

Table 5: Mean Values of Neurological Examination Parameters

\begin{tabular}{lcc}
\hline \hline Parameters & $\begin{array}{c}\text { Spastic Side } \\
\text { Before Treatment }\end{array}$ & $\begin{array}{c}\text { Spastic Side } \\
\text { After Treatment }\end{array}$ \\
\hline Tendon reflexes-points & 3.2 & 3.0 \\
Muscle tone-points & 2.5 & 1.2 \\
Muscle tone-Baclofen & 2.3 & 1.4 \\
Muscle strength-points & 2.2 & 2.2 \\
Ankle clonus-\% patients & 18.3 & 12.7 \\
Babinski sign-\% patients & 48.9 & 40.0 \\
Babinski sign-Baclofen & 53.3 & 33.3 \\
\hline
\end{tabular}

The mean values are calculated across all four patient groups, as there are no significant $(\mathrm{p}<0.1)$ differences between groups, except for muscle tone and Babinski sign after Baclofen. 
ratios are increased. The thresholds for the H-reflex with minimal and with maximal amplitude are decreased. The mean and maximal F-wave amplitudes, as well as the amplitude ratios are increased. The persistence and number of F-wave phases are increased and the F-wave duration is prolonged. However, these electromyographic measurements do not correlate with the degree of spasticity. The reason for this lack of correlation may be that electromyographical methods assess only one of many pathophysiological mechanisms of spasticity. These alterations of TA and H-reflex parameters are well known. However, the literature has not paid much attention to H-reflex thresholds, and these results show that they can also be used to assess the excitability of the lower motoneurone.

As regards F-wave, there are reports in the literature of an increase in its persistence and mean amplitude ${ }^{16,18,19}$ and a few reports of an increased $\mathrm{F}$-wave maximal amplitude ${ }^{17,41}$ in spasticity. Our results reveal other alterations in F-wave parameters in spasticity: an increase in the number of phases and the duration. All F-wave parameters depend on one common factor the lower motoneurone excitability. ${ }^{8,17,18,33}$

Treatment did not affect the TA- and H-reflex measurements in spite of a clinically observable reduction in spasticity. Other studies have reported that TA- and H-reflexes are not reliable methods for assessing spasticity, since they did not change after decreases in muscle tone. ${ }^{2}$

It is therefore impressive that all treatments influenced Fwave parameters equally well. The alpha-motoneurones are the final common pathway, integrating all segmental and suprasegmental excitatory and inhibitory influences. Consequently, any change in segmental gamma-motoneurones or interneurons would alter the alpha motoneurone excitability. This is probably the reason why myorelaxants like Baclofen and Sirdalud, which are known not to exert their effects directly upon alpha motoneurones could have influenced the F-wave parameters. However, these methods give no information about the pathophysiology since it is not possible to distinguish between primary and secondary changes in alpha-motoneurone excitability. For more detailed analysis of spasticity and myorelaxant action it will be necessary to examine other pathophysiological mechanisms. Increased excitability of the alpha-motoneurone is only one of many mechanisms of spasticity.

The literature about changes in motoneurone excitability after treatment of spasticity is controversial. In all these investigations only TA- and $\mathrm{H}$-reflexes were studied except for a single report of $\mathrm{F}$-wave changes after chronic cerebellar electrostimulation. ${ }^{13}$ The present study has shown a great difference between the TA- and H-reflexes and the F-wave in regard to the effects of treatment. This could be explained by the differences between the methods. The H-reflex and TA-reflex depend not only on the excitability of alpha-motoneurone, but also on the activity of gamma-motoneurones and presynaptic inhibition.9,42 F-wave parameters depend solely on the excitability of the alpha-motoneurone. This is probably the reason why the F-wave method is so much better at detecting an effect of treatment.

In conclusion, TA- and H-reflexes are not sensitive enough to assess changes in the excitability of the lower motoneurone. Aside from the fact that their parameters do not depend solely on the excitability of the lower motoneurone, they have some other disadvantages: special conditions are needed to examine both reflexes ${ }^{4}$ and their investigation is restricted to the lower limbs. On the other hand, the F-wave is easy to observe in both upper and lower limbs and no special recording conditions are needed. It depends only on motoneurone excitability and is sensitive enough to monitor the effects of treatment for spasticity.

\section{REFERENCES}

1. Diamantopoulos E, Olsen PZ. Excitability of motor neurons in spinal shock in man. J Neurol Neurosurg Psychiatry 1967; 30: 427-431.

2. Matthews WB. Ratio of maximum H-reflex to maximum $M$ response as a measure of spasticity. J Neurol Neurosurg Psychiatry 1966; 29: 201-204.

3. Davies TW. Definition of human reflex excitability by statistical analysis of quantal EMG responses. Brain Res 1984; 293: 386389.

4. Hugon M. Methodology of the Hoffmann reflex in man. In: Desmedt JE, ed. New Developments in Electromyography and Clinical Neurophysiology. Basel: Karger, 1973; 277-293.

5. Magladery JW, McDougal DB. Electrophysiological studies of nerve and reflex activity in normal man. I. Identification of certain reflexes in electromyogram and the conduction velocity of peripheral nerve fibres. Bull Johns Hopkins Hosp 1950; 86: 265290.

6. Dawson GD, Merton PA. "Recurrent" discharges from motoneurones. Abstracts 2nd International Congress of Physiological Sciences, Bruxelles 1956; 221-222.

7. Gassel MM, Marchiafava PL, Pompeiano O. Modulation of the recurrent discharge of alpha motoneurons in decerebrate and spinal cats. Arch Ital Biol 1965; 103: 1-14.

8. Schiller HH, Staolberg E. F-responses studied with single fibre EMG in normal subjects and spastic patients. J Neurol Neurosurg Psychiatry 1978; 41: 45-53.

9. Wong PKH, Verrier M, Ashby P. The effect of vibration on the Fwave in normal man. Electromyogr Clin Neurophysiol 1977; 17: 319-329.

10. Fisher MA, Shahani BT, Young RR. Quantitative assessment of excitability at segmental levels of the central nervous system caudal to acute lesions. Neurology 1076; 26: 366-367.

11. Fisher MA, Shahani BT, Young RR. Assessing segmental excitability after acute rostral lesions. I. The F-response. Neurology (NY) 1978; 28: 1265-1271.

12. Delwaide PJ. Electrophysiological analysis of the mode of action of muscle relaxants in spasticity. Ann Neurol 1985; 17: 90-95.

13. Fisher MA, Penn RD. Evidence for changes in segmental motoneurone pools by chronic cerebellar stimulation and its clinical significance. J Neurol Neurosurg Psychiatry 1978; 41: 630-635.

14. McLellan DL. Effect of Baclofen upon monosynaptic and tonic vibration reflexes in patients with spasticity. J Neurol Neurosurg Psychiatry 1973; 36: 555-560.

15. Knutsson E, Lindblom U, Martensson A. Differences in effects on gamma and alpha spasticity induced by the GABA derivative Baclofen (Lioresal). Brain 1973; 96: 29-46.

16. Eisen A, Odusote K. Amplitude of the F-wave: a potential means of documenting spasticity. Neurology (NY) 1979; 29: 13061309.

17. Liberson WT, Chen LCY, Fok SK, et al. "H"-reflexes and "F"waves in hemiplegics. Electromyogr Clin Neurophysiol 1977; 17: 247-264.

18. Fisher MA. F-response analysis of motor disorders of central origin. J Neurol Sci 1983; 62: 13-22.

19. Fisher MA. F/M ratios in polyneuropathy and spastic hyperreflexia. Muscle \& Nerve 1988; 2: 217-222.

20. Basmajian JV, Shankardass K, Russel D, et al. Treatment for spasticity: double blind study of a new drug. Arch Phys Med Rehabil 1984; 65: 698-701.

21. Lossius R, Dietrichson P, Lunde PKM. Effect of diazepam and desmethyldiazepam on spasticity and rigidity. A quantitative study of reflexes and plasma concentrations. Acta Neurol Scand $1980 ; 61: 378-383$. 
22. Wiesendanger $M$, Chapman $C E$, Macpherson $J$, et al. Neurophysiological investigations of tizanidine. In: Conrad B, Benecke R, Bauer HJ, eds. Die Klinische Wertung der Spastizitat. Stuttgart: FK Schattauer Verlag, 1984; 39-55.

23. Lapierre Y, Bonchard S, Tansey C, et al. Treatment of spasticity with tizanidine in multiple sclerosis. Can J Neurol Sci 1987; 14: 513-517.

24. Sica REP, Bronstein A. Changes in the excitability of segmental motoneurone pools by chronic cerebellar dentate nucleus stimulation. Electromyogr Clin Neurophysiol 1984; 24: 163-176.

25. McLellan DL, Selwyn M. Time course of clinical and physiological effects of stimulation of the cerebellar surface in patients with spasticity. J Neurol Neurosurg Psychiatry 1978; 41: 150-160.

26. Minitrijevic MR, Illis LS, Nakajima K, et al. Spinal cord stimulation for the control of spasticity in patients with chronic spinal cord injury: II. Neurophysiological observations. CNS Trauma 1986; 3: 145-152.

27. Nakamura S. Evaluation of spinal cord stimulation for postapoplectic spastic hemiplegia. Neurosurgery 1985; 17: 253-259.

28. Davidoff RA. Effects of Baclofen on synaptic activity in the spinal cord. In: Feldman RG, Young RR, Koella WP, eds. Spasticity: Disordered Motor Control. Chicago: Year Book Medical Publishers, 1980; 335-344.

29. Duncan GW, Shahani BT, Young RR. An evaluation of Baclofen treatment for certain symptoms in patients with spinal cord lesions. Neurology 1976; 26: 441-446.

30. Schmidt HT, Lee RH, Spehlmann R. Comparison of dantrolene sodium and diazepam in the treatment of spasticity. J Neurol Neurosurg Psychiatry 1976; 39: 350-356.

31. Cioni B, Meglio M, Zamponi A. Effect of spinal cord stimulation on motor performances in hemiplegics. Stereotact Funct Neurosurgery $1989 ; 52 ; 42-55$.
32. Crayton JW, King S. Inter-individual variability of the H-reflex in normal subjects. Electromyogr Clin Neurophysiol 1981; 21: 183200.

33. Peioglou-Harmoussi S, Howel D, Fawcett PRW, et al. F-response behaviour in a control population. J Neurol Neurosurg Psychiatry $1985 ; 48: 1152-1158$.

34. Hoang D. Acupuncture therapy for paralysis due to stroke and multiple sclerosis. Am J Acupuncture 1981; 9: 129-138.

35. Stux G. Efficacy of acupuncture in spastic disorders of skeletal muscle. Am J Acupuncture 1979; 2: 167-169.

36. Burke D, Hammond C, Skuse N, et al. A phenothiazine derivative in the treatment of spasticity. J Neurol Neurosurg Psychiatry 1975; 38: 469-474.

37. Jones RF, Burke D, Marosszeky JE, et al. A new agent for the control of spasticity. J Neurol Neurosurg Psychiatry 1970; 33: 464468.

38. Bishop B. Machover S, Johnston R, et al. A quantitative assessment of gamma-motoneuron contribution to the Achilles tendon reflex in normal subjects. Arch Phys Med Rehabil 1986; 49: 145-154.

39. Stam J, Tan KM. Tendon reflex variability and method of stimulation. Electroencephalogr Clin Neurophysiol 1987; 67: 463-467.

40. Winer BJ. Statistical principles in experimental design. London: McGram-Hill 1970;672.

41. Potts FA, Shahani BT, Young RR. F-response amplitude and its relationship to the motor unit. Neurology (NY) 1981; 31: 66.

42. Delwaide PJ. Human monosynaptic reflexes and presynaptic inhibition. In: Desmedt JE, ed. New Developments in Electromyography and Clinical Neurophysiology. Basel: Karger, $1973 ; 508-522$. 